OPEN ACCESS

Edited by:

Abdur Rauf,

University of Swabi, Pakistan

Reviewed by:

Himanshu Kathuria,

National University of Singapore,

Singapore

Anees Ahmed Khalil,

University of Lahore, Pakistan

*Correspondence:

Chang-Yan Li

fmmli@163.com

Xiao-Ming Yang

xiaomingyang@sina.com

Specialty section:

This article was submitted to

Predictive Toxicology,

a section of the journal

Frontiers in Pharmacology

Received: 18 May 2021

Accepted: 30 July 2021

Published: 10 August 2021

Citation:

Luo T, Zhang F-X, Zhao K, Gao H-Y, Zhang S-G, Wang L, Dou G-F, Liu T,

Yu $M$, Zhan $Y-Q$, Chen $H$, Yang $X-M$

and Li C-Y (2021) Preclinical

Pharmacokinetics, Tissue Distribution, and Primary Safety Evaluation of Indo5,

a Novel Selective Inhibitor of c-Met

and Trks.

Front. Pharmacol. 12:711126.

doi: 10.3389/fphar.2021.711126

\section{Preclinical Pharmacokinetics, Tissue Distribution, and Primary Safety Evaluation of Indo5, a Novel Selective Inhibitor of c-Met and Trks}

Teng Luo ${ }^{1,2,5}$, Fei-Xiang Zhang ${ }^{1}$, Ke Zhao ${ }^{1}$, Hui-Ying Gao ${ }^{1}$, Shou-Guo Zhang ${ }^{2}$, Lin Wang ${ }^{2}$, Gui-Fang Dou ${ }^{2}$, Ting Liu ${ }^{3}$, Miao Yu ${ }^{1}$, Yi-Qun Zhan ${ }^{1}$, Hui Chen ${ }^{1}$, Xiao-Ming Yang ${ }^{1,4 \star}$ and Chang-Yan $\mathrm{Li}^{1,3 *}$

${ }^{1}$ State Key Laboratory of Proteomics, Beijing Proteome Research Center, National Center for Protein Sciences (Beijing), Beijing Institute of Lifeomics, Beijing, China, ${ }^{2}$ Beijing Institute of Radiation Medicine, Beijing, China, ${ }^{3}$ School of Basic Medical Sciences, Anhui Medical University, Hefei, China, ${ }^{4}$ Department of Pharmaceutical Engineering, School of Chemical Engineering and Technology, Tianjin University, Tianjin, China, ${ }^{5}$ Institute of NBC Defence, Beijing, China

The compound [3-(1H-benzimidazol-2-methylene)-5-(2-methylphenylaminosulfo)-2indolone], known as Indo5, is a novel selective inhibitor of c-Met and Trks, and it is a promising anticancer candidate against hepatocellular carcinoma (HCC). Assessing the pharmacokinetic properties, tissue distribution, and toxicity of Indo5 is critical for its medicinal evaluation. A series of sensitive and specific liquid chromatography-tandem mass spectrometry methods were developed and validated to determine the concentration of Indo5 in rat plasma and tissue homogenates. These methods were then applied to investigate the pharmacokinetics and tissue distribution of Indo5 in rats. After intravenous injection of Indo5, the maximum concentration $\left(\mathrm{C}_{\max }\right)$ and the time at which $C_{\max }$ was reached $\left(T_{\max }\right)$ were $1,565.3 \pm 286.2 \mathrm{ng} / \mathrm{ml}$ and $1 \mathrm{~min}$, respectively. After oral administration, $C_{\max }$ and $T_{\max }$ were $54.7 \pm 10.4 \mathrm{ng} / \mathrm{ml}$ and $2.0 \pm 0.48 \mathrm{~h}$, respectively. We calculated the absolute oral bioavailability of Indo5 in rats to be $1.59 \%$. Following intravenous injection, the concentrations of Indo5 in various tissues showed the following order: liver $>$ kidney $\approx$ heart $>$ lung $\approx$ large intestine $\approx$ small intestine $\approx$ stomach $>$ spleen $>$ brain $\approx$ testes; hence, Indo5 distributed highest in the liver and could not cross the blood-brain or blood-testes barriers. Continuous injection of Indo5 for 21 days did not lead to liver injury, considering unchanged ALT and AST levels, normal histological architecture of the liver, and normal number and frequencies of immune cells in the liver, indicating a very low toxicity of Indo5 in vivo. Collectively, our findings provide a comprehensive understanding of the biological actions of Indo5 in vivo and further support its development as an antitumor treatment for HCC patients.

Keywords: Indo5, hepatocellular carcinoma, tissue distribution, toxicity, pharmacokinetic study 


\section{INTRODUCTION}

Hepatocellular carcinoma (HCC) accounts for about $80-90 \%$ of primary liver cancers (Llovet et al., 2008; Pan et al., 2011; Stewart and Wild, 2014; Sia et al., 2017). The incidence and mortality rates of HCC have been increasing for decades, with approximately 800,000 new cases occurring every year worldwide (Sia et al., 2017; Bertot and Adams, 2019). Limited treatment options with marginal clinical benefits are available for patients with HCC. Systemic therapy, particularly in the form of conventional cytotoxic drugs, is, in general, ineffective. In recent years, molecular-targeted therapies have been used to treat various types of cancer, including liver cancer. This approach inhibits the growth of tumor cells by interfering with molecules involved in carcinogenesis; thus, molecular-targeted therapy is more selective and specific than cytotoxic chemotherapy (Alqahtani et al., 2019). The first targeted, systemic therapy approved for the treatment of advanced HCC by the US Food and Drug Administration (FDA) in 2007 was based on the multityrosine kinase inhibitor sorafenib (Shen et al., 2013; Stotz et al., 2015). Nevertheless, sorafenib continued to show severe treatment-related adverse effects, such as diarrhea, nausea, vomiting, anorexia, fatigue, hand-and-foot skin reactions, hypertension, bleeding risk, and kidney toxicity (Llovet et al., 2008; Cheng et al., 2009; Li et al., 2015a). Regorafenib is the second-line targeted therapy for HCC and shows several adverse effects, such as severe liver injury, hemorrhage, gastrointestinal perforation, dermatological toxicity, and cardiac ischemia (George et al., 2012; Bruix et al., 2013; Grothey et al., 2013; Bruix et al., 2017). The inability of HCC patients to tolerate adverse effects often leads to a reduction in the doses of these drugs or cessation of their use, thereby diminishing the treatment efficacy. Therefore, development of novel molecular-targeted therapies for HCC with low toxicity or fewer adverse effects is urgently required.

The compound (3-(1H-benzimidazol-2-methylene)-5-(2methylphenylaminosulfo)-2-indolone), known as Indo5, is a novel lead compound containing an indolone core, which has been identified as a versatile scaffold for the development of protein kinase inhibitors (Sun et al., 1998). Indo5 has been shown to selectively inhibit the kinase activities of c-Met, TrkA, and TrkB with a half-maximal inhibitory concentration of $14.37,28$, and $25 \mathrm{nM}$, respectively, (Luo et al., 2019). Indo5 has been shown to abrogate HGF-induced c-Met signaling activation and BDNF/ NGF-induced Trks signaling activation, as well as c-Met or TrkBmediated cell transformation and migration. Furthermore, Indo5 significantly decreases the growth of HCC cells in xenografttransplanted mice and increases the survival of mice with hepatic orthotopic tumors. Those findings have indicated that Indo5 is associated with marked suppression of HCC cells co-expressing c-Met and Trks, which supports the clinical development of Indo5 as an antitumor treatment for HCC patients with coactive c-Met and Trks signaling. Hence, a thorough understanding of the biological actions of Indo5 in vivo is critical for its medical application.

Here, we investigate the preclinical pharmacokinetics, tissue distribution, and primary safety of Indo5 in vivo. Our findings further support its development as an antitumor treatment for HCC patients.

\section{MATERIALS AND METHODS}

\section{Chemicals and Reagents}

Indo5 was synthesized as described previously (US Patent Number: 9642839B2). Its purity was determined using highperformance liquid chromatography (HPLC), and the compound was used as the reference standard because of its high purity (>99\%). The molecular structure of Indo5 was characterized using Fourier-transform infrared (FT-IR) spectroscopy, ${ }^{1} \mathrm{H}$ and ${ }^{13} \mathrm{C}$ nuclear magnetic resonance $\left({ }^{1} \mathrm{H}\right.$ and $\left.{ }^{13} \mathrm{C} \mathrm{NMR}\right)$, mass spectrometry (MS), and elemental analyses. These analyses were conducted at a laboratory specializing in pharmaceutical analysis.

The internal standard (IS), terfenadine, was purchased from Sigma-Aldrich (St. Louis, MO, United States). HPLC-grade water was obtained from Watson's Food and Beverage (Guangzhou, China). HPLC-grade acetonitrile and HPLC-grade methanol were purchased from Thermo Fisher Scientific (Waltham, MA, United States). HPLC-grade formic acid and dimethyl sulfoxide (DMSO) were obtained from Sigma-Aldrich. The anesthetic phenobarbital for veterinary use was acquired from Wuhan Dongkang Source Technology (Wuhan, China). Heparin (1000 $\mathrm{UI} / \mathrm{ml}$ ) and physiologic saline $(0.9 \%)$ were purchased from Sinopharm Chemical Reagents (Shanghai, China).

\section{Indo5 Formulation}

Indo5 (10 mg) was dissolved in $10 \mathrm{ml}$ DMSO. The formulation was a clear-yellow solution, which was vortexed for $3 \mathrm{~min}$ and sterilized by passing through a $0.22-\mu \mathrm{m}$ filter. A final concentration of $1 \mathrm{mg} / \mathrm{ml}$ was obtained. The solution was stored at $4^{\circ} \mathrm{C}$ and used to manufacture standards.

\section{Animals}

Male Wistar rats $(300 \pm 20 \mathrm{~g})$ and mice (5-6 weeks old) were purchased from Beijing Vital River Laboratory Animal Technology (Beijing, China) and allowed to acclimate to their surroundings for 7 days. All of the animals were housed in individually ventilated cages in specific pathogen-free conditions at the animal facility of our institute. They were exposed to a 12-h light-dark cycle and allowed free access to food and water. The protocol for animal experiments was approved by the Animal Ethics Committee of the Academy of Military Medical Science (Beijing, China), and all of the experiments were conducted in accordance with the National Institutes of Health guidelines.

\section{Instrumentation and Analytical Conditions HPLC Conditions}

Chromatography was undertaken on an LC-20AD series HPLC system (Shimadzu, Kyoto, Japan) equipped with a vacuum degasser, a binary pump, an autosampler, and a thermostat column oven. Separation of Indo5 was carried out on a Biobasic-18 column $(5 \mu \mathrm{m}, 2.1 \mathrm{~mm} \times 50 \mathrm{~mm}$; Thermo Fisher 
Scientific) at a flow rate of $500 \mu \mathrm{l} / \mathrm{min}$ and column temperature of $30^{\circ} \mathrm{C}$. The injection volume was $10 \mu \mathrm{l}$.

\section{MS/MS Conditions}

An API4000 quadrupole mass spectrometer (Sciex, Framingham, MA, United States) was used for the analyses. The MS/MS conditions were as follows: gas temperature, $325^{\circ} \mathrm{C}$; drying gas flow, $7 \mathrm{~L} / \mathrm{min}$; nebulizer pressure, $45 \mathrm{psi}$; Vcap voltage, 3,500 V; sheath-gas temperature, $350^{\circ} \mathrm{C}$; sheath-gas flow, $9 \mathrm{~L} / \mathrm{min}$; and nozzle voltage, $0 \mathrm{~V}$. The transition for multiple reaction monitoring $(\mathrm{MRM})$ was $m / z 431.1 \rightarrow 232.2$ for Indo5.

Data on drug concentration in blood were collected, processed, and analyzed using Analyst 1.6 (Sciex). A linear weighting factor $=1 / \mathrm{X}^{2}$ model was used to process the data. An individual drug concentration in blood lower than the lower limit of quantification (LLOQ) was marked as "BQL" and recorded as zero. The above-mentioned calculations were completed using Excel ${ }^{\mathrm{TM}} 2016$ (Microsoft, Redmond, WA, United States).

\section{Preparation of Calibration Standards and Quality Control Samples}

Calibration standards were prepared daily by diluting stock solutions. Briefly, appropriate volumes of stock solution were spiked into $100 \mu \mathrm{l}$ of blank plasma and tissue homogenate. Then, the samples were vortexed for $3 \mathrm{~min}$. Next, appropriate volumes of acetonitrile were added until each sample reached a final volume of $500 \mu \mathrm{l}$; these samples were centrifuged at $10,000 \mathrm{~g}$ using an SL eight Small Benchtop Centrifuge (Thermo Fisher Scientific) for $10 \mathrm{~min}$ at room temperature. Finally, the supernatant $(40 \mu \mathrm{l})$ was injected into the HPLC/MS system. Standard solutions were prepared in triplicate for seven calibration points, and the final concentrations obtained were $1,2,5,20,50,100$, and $500 \mathrm{ng} / \mathrm{ml}$.

Calibration curves were constructed in triplicate by plotting known concentrations of the standard versus the detector response area. In the same way, a separate set of stock solutions was prepared for QC samples to determine accuracy and precision.

\section{Method Validation}

The developed method was validated in accordance with the bioanalytical guidance from the FDA (FDA, Guidance for Industry Bioanalytical Method Validation, 2018), with determination of the following parameters: linearity; withinrun and between-run accuracy and precision; recovery; LLOQ; limit of detection (LOD); selectivity; and stability.

\section{Pharmacokinetic Studies}

For intravenous (IV) treatment, Indo5 was dissolved in DMSO (solution, $1 \mathrm{mg} / \mathrm{ml}$ ) and injected into the lateral tail vein of rats $(1 \mathrm{mg} / \mathrm{kg}, n=3)$. For intragastric treatment, Indo5 was dissolved in $5 \% \mathrm{CMC}-\mathrm{Na}$ (suspension, $20 \mathrm{mg} / \mathrm{ml}$ ). The rats were orally administered with Indo5 $(100 \mathrm{mg} / \mathrm{kg}, n=3)$ using a $20-\mathrm{G}$ gavage needle. All of the animals were given a standard diet $4 \mathrm{~h}$ after the dosing. Blood samples (approximately $400 \mu \mathrm{l}$ ) were collected from each rat and placed into heparinized tubes before the dosing, and at 5, 15, 30, 60, 120, 240, and $480 \mathrm{~min}$ after the dosing. Plasma $(100 \mu \mathrm{l})$ was harvested by centrifuging blood samples at $3,600 \mathrm{~g}$ for $10 \mathrm{~min}$ at room temperature followed by immediate processing for the analyses.

\section{Sample Preparation}

Briefly, $400 \mu \mathrm{l}$ acetonitrile was added to $100 \mu \mathrm{l}$ rat plasma or tissue homogenate, vortexed for $30 \mathrm{~s}$, and centrifuged at 10,000 $\mathrm{g}$ for $10 \mathrm{~min}$ at room temperature to precipitate proteins. Subsequently, the supernatant $(40 \mu \mathrm{l})$ was introduced into the HPLC/MS system. Plasma or tissue concentrations of Indo5 were determined using HPLC-MS/MS validated for pharmacokinetics.

\section{Analyses of Pharmacokinetic Data}

The plasma concentration-time data obtained after intravenous and intragastric administrations were subjected to noncompartmental analyses based on the statistical moment theory. Pharmacokinetic parameters were calculated using WinNorlin 5.2 (Certara; www.certara.com/). These parameters included the maximum plasma concentration $\left(\mathrm{C}_{\max }\right)$, time to reach $C_{\max }\left(T_{\max }\right)$, elimination half-life $\left(t_{1 / 2}\right)$, area under the plasma concentration-time curve from time zero to infinity $\left(\mathrm{AUC}_{0-\infty}\right)$, mean residence time (MRT), and clearance $(\mathrm{CL})$. The absolute oral bioavailability was calculated by dividing the $\mathrm{AUC}_{\text {tot }}$ obtained from oral administration by the $\mathrm{AUC}_{\text {tot }}$ obtained from IV administration, and the calculation was adjusted using the doses that had been administered via oral and IV routes.

\section{Tissue-Distribution Study}

Twelve male Wistar rats were given a single dose of Indo5 $(1 \mathrm{mg} / \mathrm{kg}, \mathrm{IV})$. At 2, 5, 30, 60, 120, 480, and $720 \mathrm{~min}$ after the dosing, a group of animals ( $n=4$ for each treatment time) was sacrificed. The liver, kidneys, heart, lungs, stomach, small intestine, small-intestine content, large intestine, large-intestine content, spleen, brain, and testes were dissected rapidly and harvested. All of the tissues were rinsed thoroughly in ice-cold physiologic saline to eliminate blood and other content. The tissues and contents were processed by homogenization with $0.9 \%$ saline in a $1: 3(\mathrm{w} / \mathrm{v})$ ratio. The preparation process for analyses was the same as that described for plasma.

\section{Isolation of Mononuclear Cells From Mouse Liver}

Freshly separated liver was rinsed in ice-cooled phosphatebuffered saline (PBS) and then placed on a $40-\mu \mathrm{m}$ filter. We added an appropriate amount of RPMI-1640 medium containing $2 \%$ fetal bovine serum (FBS) and used the piston of a $5-\mathrm{ml}$ syringe to squeeze the tissue blocks to the bottom of the screen until only fibrous tissue remained. The volume of cell suspension collected was $40 \mathrm{ml}$. We centrifuged the cell suspension at $50 \mathrm{~g}$ for $5 \mathrm{~min}$ at $4^{\circ} \mathrm{C}$ and collected the supernatant. Next, we centrifuged at $800 \mathrm{~g}$ for $10 \mathrm{~min}$ at $4^{\circ} \mathrm{C}$ and discarded the supernatant. The precipitate was resuspended with a solution containing $40 \%$ Percoll $^{\mathrm{TM}}$ ( $2 \mathrm{ml}$ of $90 \%$ Percoll with $2.5 \mathrm{ml}$ 


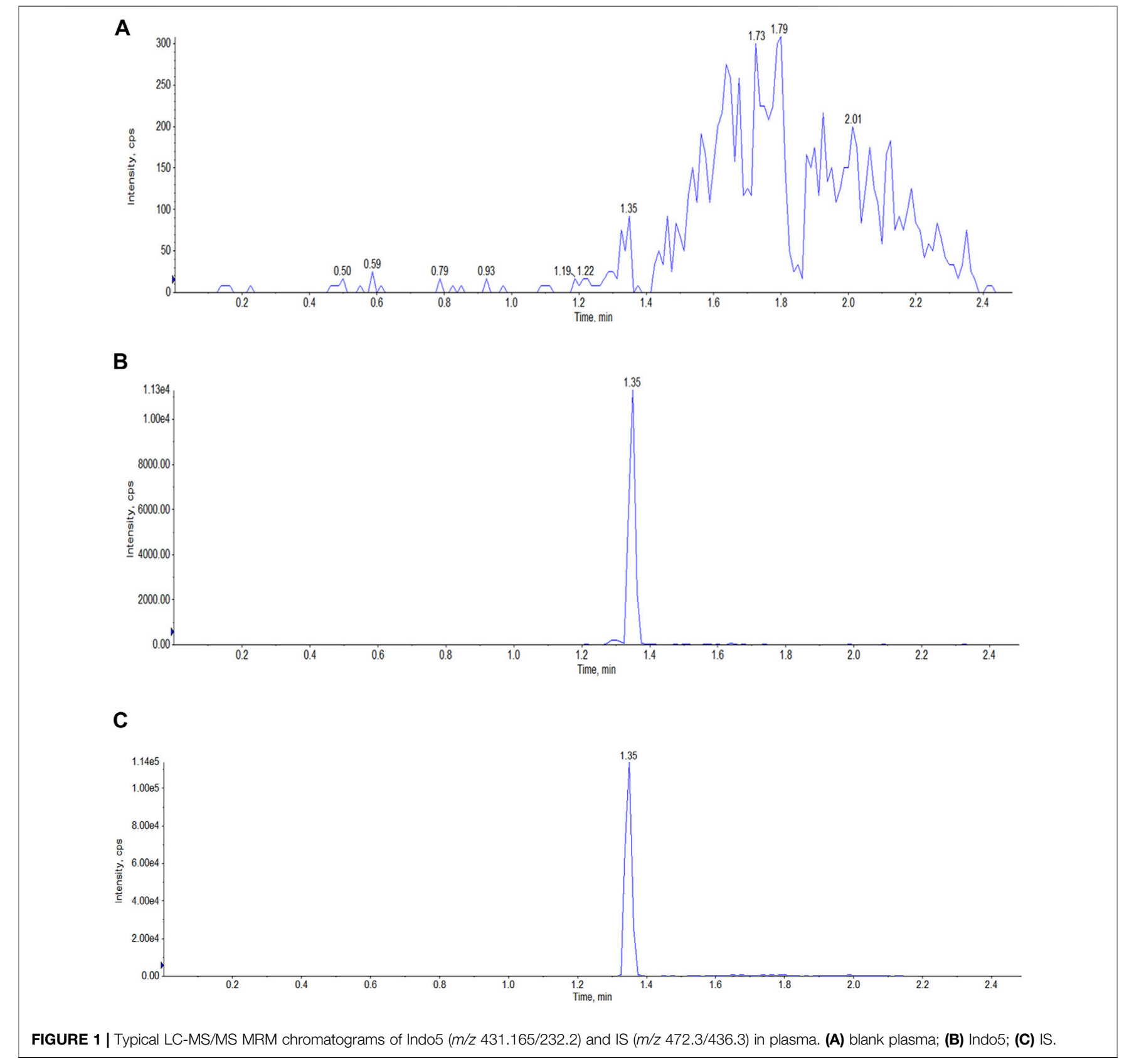

RPMI-1640 medium). We carefully added the suspension, using a capillary pipette, to a solution containing $70 \%$ Percoll (4 ml of 90\% Percoll with $1.12 \mathrm{ml}$ RPMI-1640 medium). Next, we centrifuged at $800 \mathrm{~g}$ for $20 \mathrm{~min}$ at $4^{\circ} \mathrm{C}$, removed the upper layer, took the middle layer, and added an appropriate amount of $2 \%$ FBS in RPMI-1640 medium to reach $15 \mathrm{ml}$. Then, we undertook centrifugation at $800 \mathrm{~g}$ for $10 \mathrm{~min}$ at $4^{\circ} \mathrm{C}$, removed the supernatant, and transferred it to a fresh $1.5-\mathrm{ml}$ Eppendorf $^{\mathrm{TM}}$ tube. Next, it was centrifuged at $1800 \mathrm{~g}$ for $5 \mathrm{~min}$ at room temperature and dried with absorbent paper. We added $300 \mu \mathrm{l}$ of red blood cell (RBC) lysate for resuspension, lysed the RBCs for $3 \mathrm{~min}$ at room temperature, added $1 \mathrm{ml}$ of RPMI-1640 medium with $2 \%$ FBS to stop the lysis, and centrifuged at $1800 \mathrm{~g}$ for $5 \mathrm{~min}$ at room temperature. An appropriate amount of PBS containing $2 \%$ FBS was added to resuspend the cells.

\section{Flow Cytometry}

The cell suspension was added to a $1.5-\mathrm{ml}$ Eppendorf tube, incubated with antibody for $30 \mathrm{~min}$ at $4^{\circ} \mathrm{C}$ in the dark, washed twice with $2 \%$ PBS, resuspended with $400 \mu \mathrm{l}$ of $2 \%$ PBS, and analyzed by flow cytometry. The antibodies used for labeling were as follows: cluster of differentiation (CD)3-PerCP-Cy5.5, NK1.1FITC, B220-APC, CD11c-FITC, CD11b-APC, CD4-APC, CD8$\mathrm{PE}$, and CD69-PE/Cy7; they were obtained from eBioscience (San Diego, CA, United States) or BD Biosciences (Franklin Lakes, NJ, United States). 
TABLE 1 | Calibration curve and correlation coefficients of Indo5 in biological samples.

\section{Matrix}

Plasma

Liver

Kidney

Heart

Lung

Stomach

Small intestine

Large intestine

Spleen

Brain

Testis

Small-intestine content

Large-intestine content
Calibration curve

$$
\begin{gathered}
y=1.0016 x+0.1253 \\
y=0.00101055 x+0.000254539 \\
y=0.000976907 x+0.00151646 \\
y=0.00102639 x+0.000248108 \\
y=0.000973661 x-0.000100517 \\
y=0.001531 x+0.00403645 \\
y=0.00284016 x+0.00909608 \\
y=0.00233707 x+0.00832539 \\
y=0.00258944 x+0.0060807 \\
y=0.00421543 x+0.0034438 \\
y=0.00713123 x+0.0174964 \\
y=0.00258989 x+0.00451089 \\
y=0.00384958 x+0.00737813
\end{gathered}
$$

Correlation coefficient (R)

0.9992

0.9976

0.9957

0.9968

0.9938

0.9947

0.9968

0.9916

0.9964

0.995

0.993

0.9976

0.9951

\section{Histopathology}

The tissues were fixed in 10\% formalin and embedded in paraffin. Then, 4- $\mu$ m-thick sections were stained with hematoxylin and eosin for histopathological and morphological analyses.

\section{Statistical Analysis}

All of the data were expressed as mean \pm standard deviation (SD) of at least three independent experiments. For comparisons between two groups, two-tailed Student's $t$-tests were performed. $p<0.05$ was considered statistically significant. The data were analyzed and graphed using GraphPad Prism 6.

\section{RESULTS}

\section{Method Validation}

Selectivity. Six blank samples of each matrix (plasma and tissues) were analyzed to evaluate the selectivity of our method. The samples were prepared in accordance with the method we developed. The blank samples were spiked with a standard solution of Indo5 and IS, and then analyzed; typical MRM chromatograms are shown in Figure 1. Our method demonstrated high selectivity given that there was no interference in the analyte peaks with those obtained using standards or the IS.

Linearity. Linearity was tested using calibration curves by spiking blank plasma and tissues at eight concentration levels. All of the calibration curves for Indo5 in plasma or tissue were linear over the concentration range $1-500 \mathrm{ng} / \mathrm{ml}$ with a correlation coefficient $(r)>0.99$ (Table 1).

Accuracy and precision. Accuracy and precision were evaluated at LLOQ, as well as low, medium, and high levels, with five replicates, on three separate days. The accuracy of detecting Indo5 in plasma and tissues was $85.5-112.5 \%$. Within-run and between-run precision was $<15 \%$ (Table 2). These results all met the criteria set by the FDA.

Recovery and matrix-effect. Recovery was calculated by comparing the analytical results for the extracted samples with the corresponding extracts of blanks spiked with Indo5 after extraction. The recovery effect of Indo5 at three QC levels ranged from 87.3 to $95.7 \%$ in plasma, and from 85.6 to $105.2 \%$ in the tested tissue homogenates (Table 3 ). The extraction recovery of
IS in plasma and tissues was between 95.9 and 103.4\%, indicating that protein precipitation as the sample preparation resulted in high and reproducible extraction efficiencies. The matrix effect of Indo5 at three QC levels ranged from 91.2 to $98.4 \%$ in plasma, and from 90.7 to $106.1 \%$ in the tissue homogenates, and the matrix effect of the IS in plasma and the tissues was between 93.6 and $104.5 \%$, which indicated that there was no significant ion suppression or enhancement in the LC-MS/MS method (data not shown).

\section{Plasma Distribution}

After IV (1 mg/kg in DMSO) or oral (100 mg/kg in 0.5\% CMC$\mathrm{Na})$ administration of Indo5 to rats in each treatment group $(n=$ 3 ), the plasma concentrations of Indo5 were determined using LC-MS/MS. The data obtained from each group were averaged. Figures 2, 3 show the mean plasma concentration-time curves for Indo5 after IV and oral administration, respectively. The corresponding pharmacokinetic parameters, calculated using a non-compartmental model are summarized in Table 4.

After IV administration, the plasma concentrations of Indo5 were well above the LLOQ within $2 \mathrm{~h}$ but, at $4 \mathrm{~h}$, Indo5 was not detected. For IV injection, $\mathrm{T}_{\max }$ was $1 \mathrm{~min}, \mathrm{C}_{\max }$ was $1,565.3 \pm$ $286.2 \mathrm{ng} / \mathrm{ml}, \mathrm{AUC}_{0-\mathrm{t}}$ was $158.6 \pm 27.9 \mathrm{~h} \cdot \mathrm{ng} / \mathrm{ml}, \mathrm{AUC}_{0-\infty}$ was $163.4 \pm 28.3 \mathrm{~h} \cdot \mathrm{ng} / \mathrm{ml}, \mathrm{MRT}_{0-\mathrm{t}}$ was $0.18 \pm 0.04 \mathrm{~h}$, and $\mathrm{MRT}_{0-\infty}$ was $0.26 \pm 0.06 \mathrm{~h} . \mathrm{T}_{1 / 2}$ was $0.63 \pm 0.11 \mathrm{~h}$, indicating that Indo5 had a short half-life in vivo. Moreover, Indo5 displayed a high systemic CL $(6,121.6 \pm 1,124.8 \mathrm{ml} / \mathrm{h} / \mathrm{kg})$ at the tested dose.

After oral administration, the plasma concentrations of Indo5 were above the LLOQ within $8 \mathrm{~h}$. For oral administration, $\mathrm{T}_{\max }$ was $2.0 \pm 0.48 \mathrm{~h}, \mathrm{C}_{\max }$ was $54.7 \pm 10.4 \mathrm{ng} / \mathrm{ml}, \mathrm{t}_{1 / 2}$ was $1.25 \pm$ $0.24 \mathrm{~h}, \quad \mathrm{AUC}_{0-\mathrm{t}}$ was $251.5 \pm 43.5 \mathrm{~h} \cdot \mathrm{ng} / \mathrm{ml}, \mathrm{AUC}_{0-\infty}$ was $255.7 \pm 44.9 \mathrm{~h} \cdot \mathrm{ng} / \mathrm{ml}, \mathrm{MRT}_{0-\mathrm{t}}$ was $2.87 \pm 0.61 \mathrm{~h}, \mathrm{MRT}_{0-\infty}$ was $2.99 \pm 0.63 \mathrm{~h}$, and CL was $391056.4 \pm 77,945.8 \mathrm{ml} / \mathrm{h} / \mathrm{kg}$. According to the value for $\mathrm{AUC}_{0-\infty}$ for oral administration and IV injection at $100 \mathrm{mg} / \mathrm{kg}$, the bioavailability of Indo5 was $1.59 \%$.

These results suggested that Indo5 was rapidly cleared from the plasma and had low bioavailability.

\section{Tissue Distribution}

The concentrations of Indo5 after IV administration $(1 \mathrm{mg} / \mathrm{kg})$ in the liver, kidneys, lungs, heart, spleen, stomach, large intestine, 
TABLE 2 | Accuracy, within-run and between-run precision for Indo5 in rat plasma and tissues.

\begin{tabular}{|c|c|c|c|c|c|}
\hline \multirow[t]{2}{*}{ Matrix } & \multirow[t]{2}{*}{ QC level } & \multirow[t]{2}{*}{ Nominal concentration (ng/ml) } & \multirow[t]{2}{*}{ Accuracy (\%) } & \multicolumn{2}{|c|}{ Precision (CV $\left.{ }^{\mathrm{a}} \%\right)$} \\
\hline & & & & Within-run ( $n=5$ ) & Between-run $(n=5)$ \\
\hline \multirow[t]{4}{*}{ Plasma } & $\mathrm{LLOQ}^{\mathrm{b}}$ & 1 & 88.3 & 4.3 & 14 \\
\hline & LOW & 5 & 92 & 7.9 & 11.7 \\
\hline & MEDIUM & 100 & 90 & 6.6 & 8.4 \\
\hline & $\mathrm{HIGH}$ & 500 & 97 & 2 & 5.2 \\
\hline \multirow[t]{4}{*}{ Liver } & LLOQ & 1 & 86.1 & 12.4 & 13.2 \\
\hline & LOW & 5 & 105.8 & 1.2 & 9.1 \\
\hline & MEDIUM & 100 & 94.4 & 2 & 4.8 \\
\hline & $\mathrm{HIGH}$ & 500 & 101.2 & 3.4 & 6 \\
\hline \multirow[t]{4}{*}{ Kidney } & LLOQ & 1 & 110 & 5.4 & 14.6 \\
\hline & LOW & 5 & 103 & 6.8 & 3.6 \\
\hline & MEDIUM & 100 & 98.4 & 7.4 & 13.9 \\
\hline & $\mathrm{HIGH}$ & 500 & 102.7 & 2.6 & 3.9 \\
\hline \multirow[t]{4}{*}{ Heart } & LLOQ & 1 & 86.5 & 12.7 & 12.9 \\
\hline & LOW & 5 & 106.2 & 9.4 & 11.7 \\
\hline & MEDIUM & 100 & 111.3 & 4.7 & 6.4 \\
\hline & $\mathrm{HIGH}$ & 500 & 97.9 & 2.7 & 4.1 \\
\hline \multirow[t]{4}{*}{ Lung } & LLOQ & 1 & 85.8 & 12.7 & 12.8 \\
\hline & LOW & 5 & 100.5 & 7.8 & 10.9 \\
\hline & MEDIUM & 100 & 93.2 & 10.4 & 11.6 \\
\hline & $\mathrm{HIGH}$ & 500 & 97.2 & 6.3 & 9.5 \\
\hline \multirow[t]{4}{*}{ Stomach } & LLOQ & 1 & 85.5 & 14.3 & 13.9 \\
\hline & LOW & 5 & 107.7 & 6.1 & 14.1 \\
\hline & MEDIUM & 100 & 107.4 & 6 & 7.5 \\
\hline & $\mathrm{HIGH}$ & 500 & 101.7 & 8.6 & 3.2 \\
\hline \multirow[t]{4}{*}{ Small intestine } & LLOQ & 1 & 112.4 & 9.7 & 14.7 \\
\hline & LOW & 5 & 94.6 & 2.6 & 6.5 \\
\hline & MEDIUM & 100 & 104.2 & 3.1 & 3.7 \\
\hline & $\mathrm{HIGH}$ & 500 & 102.9 & 2.5 & 3.9 \\
\hline \multirow[t]{4}{*}{ Large intestine } & LLOQ & 1 & 113.5 & 4.1 & 9.3 \\
\hline & LOW & 5 & 91.4 & 2.7 & 8.9 \\
\hline & MEDIUM & 100 & 98.3 & 4.6 & 10.9 \\
\hline & $\mathrm{HIGH}$ & 500 & 106.6 & 3.8 & 6.5 \\
\hline \multirow[t]{4}{*}{ Spleen } & LLOQ & 1 & 87.6 & 10.3 & 9.6 \\
\hline & LOW & 5 & 91.3 & 3.5 & 3.9 \\
\hline & MEDIUM & 100 & 94.2 & 2.7 & 10.1 \\
\hline & $\mathrm{HIGH}$ & 500 & 105.9 & 3.3 & 7.5 \\
\hline \multirow[t]{4}{*}{ Brain } & LLOQ & 1 & 88.6 & 12.8 & 12.5 \\
\hline & LOW & 5 & 112.1 & 8 & 11.5 \\
\hline & MEDIUM & 100 & 95.4 & 3.3 & 10.7 \\
\hline & $\mathrm{HIGH}$ & 500 & 101 & 4.3 & 5.1 \\
\hline \multirow[t]{4}{*}{ Testis } & LLOQ & 1 & 111.8 & 8.8 & 13.9 \\
\hline & LOW & 5 & 99 & 3.6 & 9.8 \\
\hline & MEDIUM & 100 & 104.3 & 8.5 & 10.3 \\
\hline & $\mathrm{HIGH}$ & 500 & 102.9 & 3.2 & 2.4 \\
\hline \multirow[t]{4}{*}{ Small-intestine content } & LLOQ & 1 & 111 & 14.7 & 12.2 \\
\hline & LOW & 5 & 92.7 & 7.2 & 10.4 \\
\hline & MEDIUM & 100 & 106.4 & 2.4 & 2.9 \\
\hline & $\mathrm{HIGH}$ & 500 & 98.3 & 4 & 3.7 \\
\hline \multirow[t]{4}{*}{ Large-intestine content } & LLOQ & 1 & 89.2 & 13.2 & 13.9 \\
\hline & LOW & 5 & 93.6 & 8.6 & 10.9 \\
\hline & MEDIUM & 100 & 106.2 & 3.3 & 9 \\
\hline & $\mathrm{HIGH}$ & 500 & 102.2 & 4.7 & 6.2 \\
\hline
\end{tabular}

${ }^{a} \mathrm{CV}$ :coefficient of variation.

${ }^{b}$ LLOQ:lower limit of quantification.

small intestine, brain, and testes at the indicated times in rats are shown in Figure 4. Indo5 was distributed rapidly and widely in the tested tissues in the following order: liver $>$ kidneys $\approx$ heart $>$ lungs $\approx$ large intestine $\approx$ small intestine $\approx$ stomach $>$ spleen $>$ brain $\approx$ testes. Indo5 was eliminated quickly from the tested tissues, and at $8 \mathrm{~h}$, it was not detectable anymore in the kidneys, heart, lungs, large intestine, small intestine, stomach, spleen, brain, or testes. Notably, the hepatic Indo5 concentration was higher than that in other tissues, and it was still detectable in the liver $8 \mathrm{~h}$ post administration. 
TABLE 3 | Recovery of Indo5 in rat plasma and tissues.

\begin{tabular}{|c|c|c|}
\hline Matrix & QC level & $\begin{array}{c}\text { Recovery \% } \\
\left(\mathbf{C V}^{\mathrm{a}} ; \boldsymbol{n}=\mathbf{5}\right)\end{array}$ \\
\hline \multirow[t]{3}{*}{ Plasma } & LOW & $87.3(3.8 \%)$ \\
\hline & MEDIUM & 95.7 (5.9\%) \\
\hline & $\mathrm{HIGH}$ & 94.1 (4.0\%) \\
\hline \multirow[t]{3}{*}{ Liver } & LOW & $92.7(5.8 \%)$ \\
\hline & MEDIUM & $96.5(2.8 \%)$ \\
\hline & $\mathrm{HIGH}$ & $103.2(5.4 \%)$ \\
\hline \multirow[t]{3}{*}{ Kidney } & LOW & $94(4.7 \%)$ \\
\hline & MEDIUM & $101(3.3 \%)$ \\
\hline & $\mathrm{HIGH}$ & $98.4(6.1 \%)$ \\
\hline \multirow[t]{3}{*}{ Heart } & LOW & 88.9 (2.4\%) \\
\hline & MEDIUM & $102.9(2.0 \%)$ \\
\hline & $\mathrm{HIGH}$ & $100.9(5.7 \%)$ \\
\hline \multirow[t]{3}{*}{ Lung } & LOW & $85.6(6.5 \%)$ \\
\hline & MEDIUM & $89.3(5.3 \%)$ \\
\hline & $\mathrm{HIGH}$ & $94.3(2.6 \%)$ \\
\hline \multirow[t]{3}{*}{ Stomach } & LOW & $95.4(3.5 \%)$ \\
\hline & MEDIUM & $104(6.0 \%)$ \\
\hline & $\mathrm{HIGH}$ & $93.1(7.0 \%)$ \\
\hline \multirow[t]{3}{*}{ Small intestine } & LOW & $86.2(4.8 \%)$ \\
\hline & MEDIUM & $89(7.3 \%)$ \\
\hline & $\mathrm{HIGH}$ & 94.7 (3.1\%) \\
\hline \multirow[t]{3}{*}{ Large intestine } & LOW & 89.5 (1.5\%) \\
\hline & MEDIUM & $95.2(3.0 \%)$ \\
\hline & $\mathrm{HIGH}$ & $101.2(5.6 \%)$ \\
\hline \multirow[t]{3}{*}{ Spleen } & LOW & $88.8(4.4 \%)$ \\
\hline & MEDIUM & $96.3(3.7 \%)$ \\
\hline & $\mathrm{HIGH}$ & $105.2(2.3 \%)$ \\
\hline \multirow[t]{3}{*}{ Brain } & LOW & $91.6(3.2 \%)$ \\
\hline & MEDIUM & $96.9(4.6 \%)$ \\
\hline & $\mathrm{HIGH}$ & $104.3(5.4 \%)$ \\
\hline \multirow[t]{3}{*}{ Testis } & LOW & $93.9(3.6 \%)$ \\
\hline & MEDIUM & $96(2.2 \%)$ \\
\hline & $\mathrm{HIGH}$ & $102.3(1.4 \%)$ \\
\hline \multirow[t]{3}{*}{ Small-intestine content } & LOW & $86.4(6.2 \%)$ \\
\hline & MEDIUM & $98.1(3.1 \%)$ \\
\hline & $\mathrm{HIGH}$ & $99.4(5.5 \%)$ \\
\hline \multirow[t]{3}{*}{ Large-intestine content } & LOW & $86(7.9 \%)$ \\
\hline & MEDIUM & $90.7(5.2 \%)$ \\
\hline & $\mathrm{HIGH}$ & $100.7(3.4 \%)$ \\
\hline
\end{tabular}

${ }^{a} \mathrm{CV}$ :coefficient of variation.

To verify the liver enrichment of Indo5, we measured the Indo5 concentration in the tissues after oral administration. Consistent with the results following IV administration, the highest concentration of Indo5 was found in the liver, and it was detectable $8 \mathrm{~h}$ post administration (Figure 5).

Taken together, these results suggested that Indo5 displayed an accumulated distribution in the liver in vivo.

\section{Toxicity}

Given that Indo5 was most distributed in the liver and had significant antitumor activity in a xenograft model and hepatic orthotopic model in mice (Luo et al., 2019), we investigated if continuous administration of Indo5 leads to liver injury. Indo5 was orally administered (p.o.) once daily for 21 days, and we evaluated its toxicity. No obvious weight loss or other symptoms were observed with continuous injection of Indo5. The overall health of the animals was not adversely
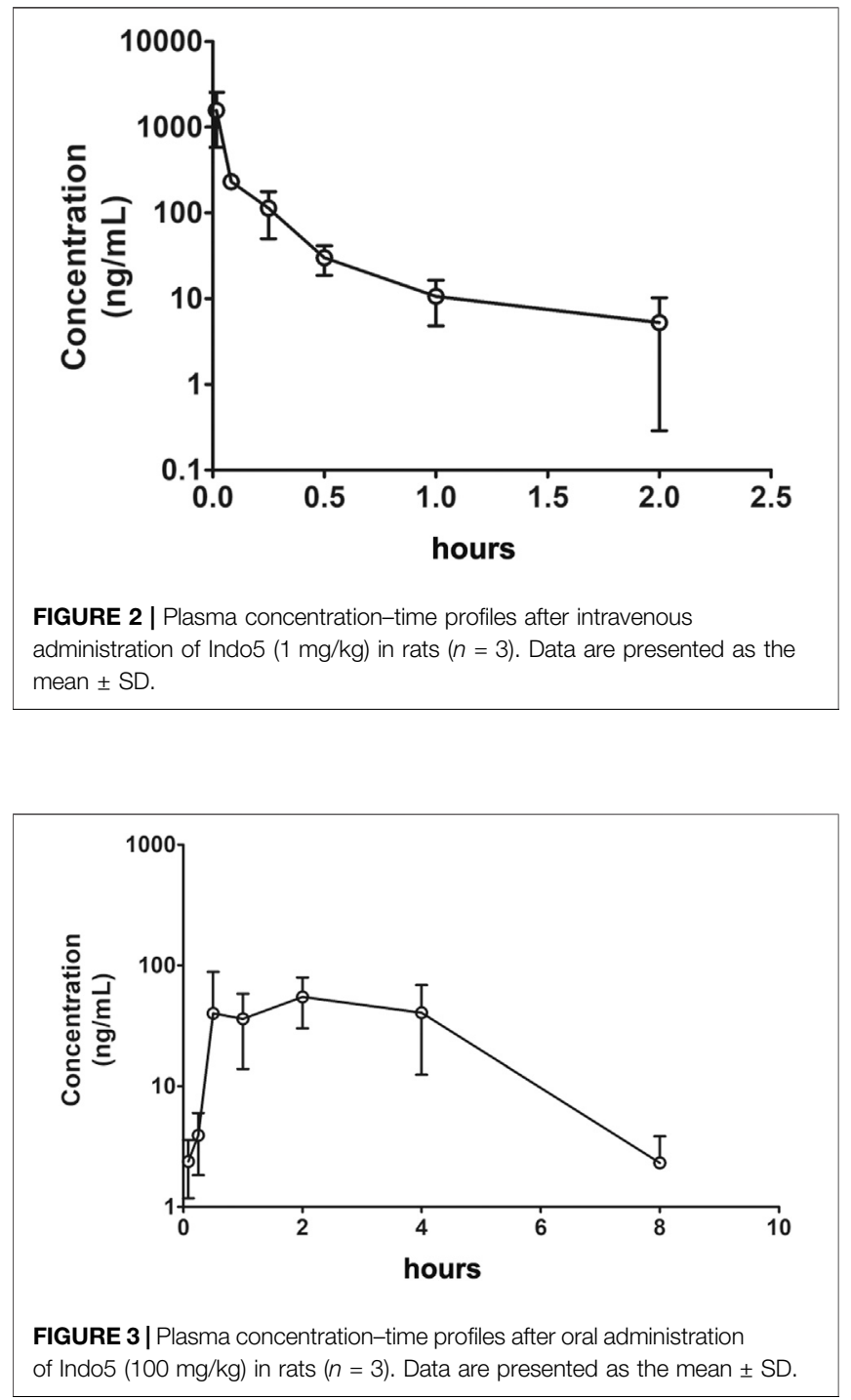

affected (data not shown). The levels of alanine aminotransferase (ALT) and aspartate aminotransferase (AST) in serum did not change significantly after Indo5 administration (Figures 6A,B; $p>0.05$ ). Histological analysis of liver tissue revealed no pathological changes in Indo5-treated mice compared with the solvent-control group, i.e., a normal lobular architecture with a central vein and radiating hepatic cords were observed (Figure 6C). Often, liver injury leads to infiltration or activation of immune cells in liver tissue. We thus investigated the number of liver mononuclear cells and frequencies of various immune cells, including T cells, natural killer cells, natural killer T cells, $\mathrm{B}$ cells, dendritic cells, and myeloid cells. The frequencies of T-cell subsets $\left(\mathrm{CD} 4^{+}, \mathrm{CD}^{+}\right)$and activated T cells $\left(\mathrm{CD} 4^{+} \mathrm{CD} 69^{+}\right.$, $\left.\mathrm{CD} 8^{+} \mathrm{CD} 69^{+}\right)$were also measured. Continuous administration of Indo5 for 21 days did not affect the number or frequencies of immune cells in the liver (Figure 7; $p>0.05$ ).

These results suggested that Indo5 did not show obvious toxicity. 
TABLE 4 | Main pharmacokinetic parameters of Indo5 following intravenous or oral administration.

\section{Parameters}

Intravenous administration (IV) $1 \mathrm{mg} / \mathrm{kg}$

$t_{1 / 2}(h)$

$\mathrm{T}_{\text {max }}(\mathrm{h})$

$\mathrm{C}_{\max }(\mathrm{ng} / \mathrm{ml})$

$\mathrm{AUC}_{0-\mathrm{t}}\left(\mathrm{h}^{\star} \mathrm{ng} / \mathrm{ml}\right)$

$\mathrm{AUC}_{0-\infty}\left(\mathrm{h}^{\star} \mathrm{ng} / \mathrm{ml}\right)$

Vd $(\mathrm{ml} / \mathrm{kg})$

$\mathrm{CL}(\mathrm{ml} / \mathrm{h} / \mathrm{kg})$

$\mathrm{MRT}_{\text {O-t }}$ (h)

$\mathrm{MRT}_{0-\infty}(\mathrm{h})$
$0.63 \pm 0.11$
0.0167
$1,565.3 \pm 286.2$
$158.6 \pm 27.9$
$163.4 \pm 28.3$
$5,588 \pm 9,433.8$
$6,121.6 \pm 1,124.8$
$0.18 \pm 0.04$
$0.26 \pm 0.06$

Oral administration (p.o.) $100 \mathrm{mg} / \mathrm{kg}$

$1.25 \pm 0.24$

$2.0 \pm 0.48$

$54.7 \pm 10.4$

$251.5+43.5$

$255.7 \pm 44.9$

$706349 \pm 106941.2$

$391056.4 \pm 77,945.8$

$2.87 \pm 0.61$

$2.99 \pm 0.63$

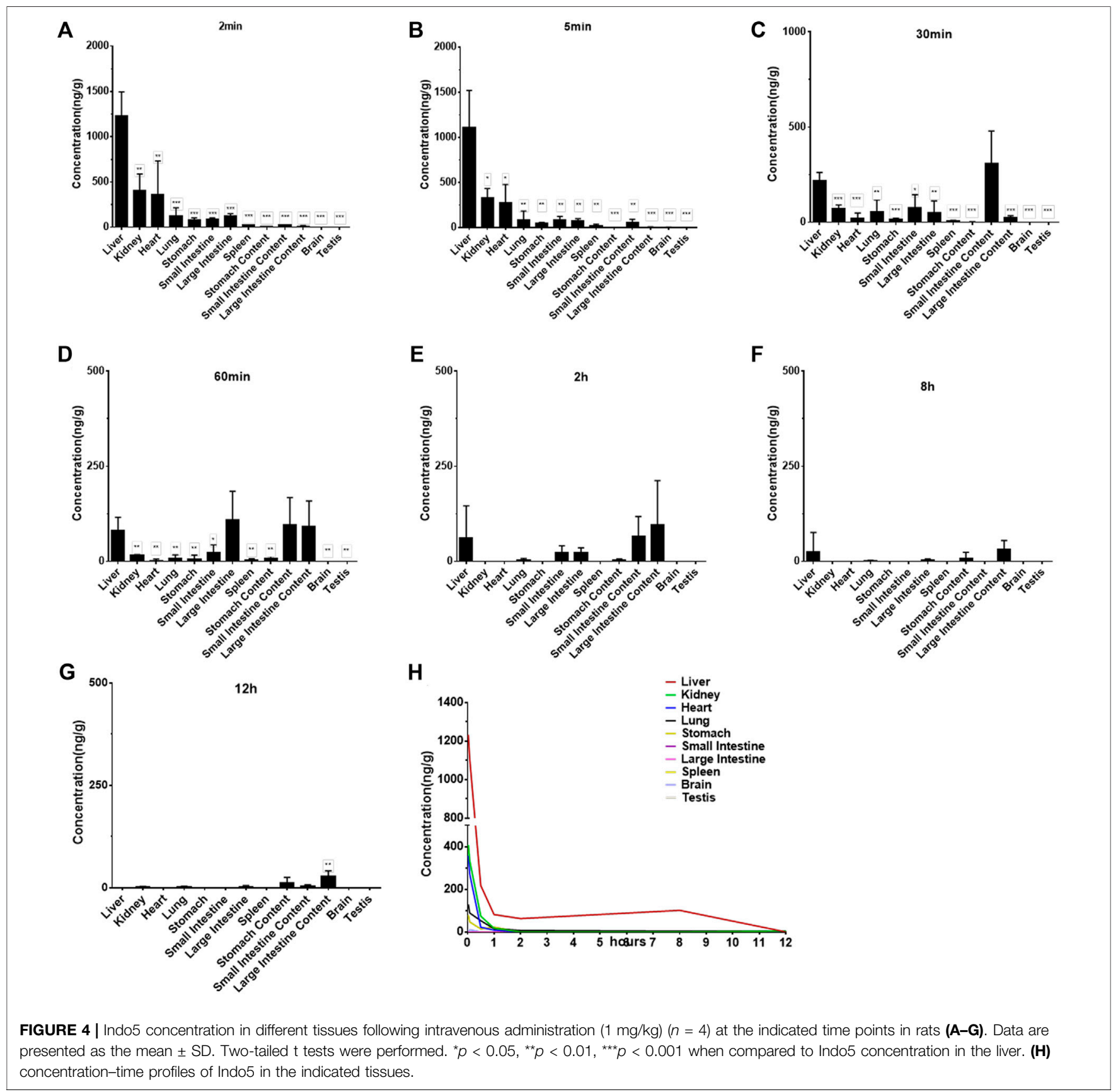




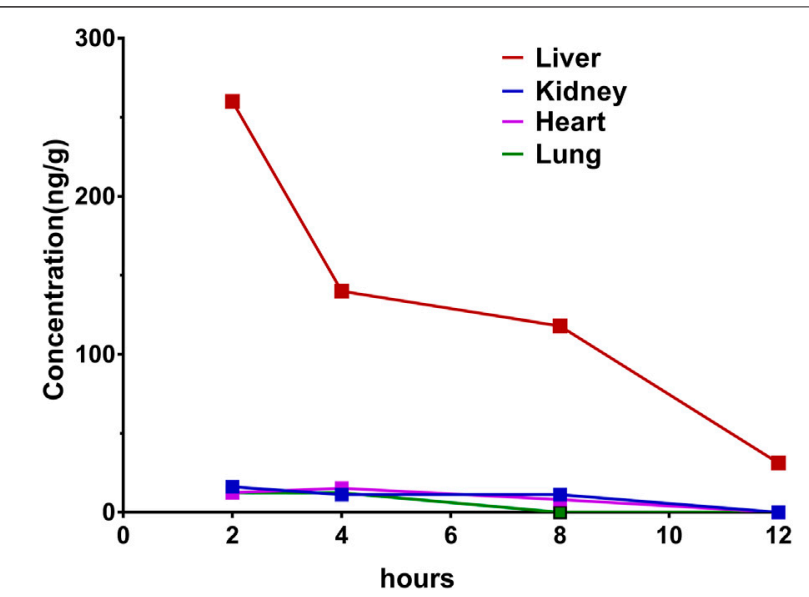

FIGURE 5 | Concentration-time profiles after oral administration of Indo5 in the rat liver, kidneys, heart, and lungs at a dose of $100 \mathrm{mg} / \mathrm{kg}(n=3)$.

\section{DISCUSSION}

Here, we developed a series of validated HPLC-MS/MS methods to measure the Indo5 concentration in plasma and tissue homogenates. To investigate Indo5 absorption, we measured the concentrations of Indo5 in rat plasma at different time intervals. After IV injection of Indo5, $\mathrm{T}_{\max }$, and $\mathrm{C}_{\max }$ were $1 \mathrm{~min}$ and $1,565.3 \pm 286.2 \mathrm{ng} / \mathrm{ml}$, respectively. $\mathrm{C}_{\max }$ of Indo5 in the oral-administration group was $54.7 \pm$ $10.4 \mathrm{ng} / \mathrm{ml}$, and it occurred at $2.0 \pm 0.48 \mathrm{~h}$. The absolute oral bioavailability of Indo5 in rats was $1.59 \%$. The tissuedistribution study suggested that Indo5 accumulated in the liver and could not cross the blood-brain or blood-testes barriers. The toxicity study suggested that continuous injection of Indo5 for 21 days did not lead to liver injury because the levels of ALT and AST were unchanged, normal histological architecture of the liver was preserved, and normal number and frequency of immune cells were found in the liver. Our findings provide a more complete understanding of the biological actions of Indo5, and also provide insights for the future modification of Indo5 formulations to increase bioavailability.

In general, the oral route for drug administration is considered more attractive than the IV route because of its greater convenience for patients and pharmacoeconomic advantages (Liu et al., 1997; Schellens et al., 2000; Oostendorp et al., 2011). We observed a low oral bioavailability of Indo5 (1.59\%) at $100 \mathrm{mg} / \mathrm{kg}$, which might have been due to the low solubility and stability of this compound. Previous studies have reported that compounds with low solubility show low oral bioavailability, for example, paclitaxel (Rowinsky et al., 1994; Huizing et al., 1995), wogonin (Talbi et al., 2014), and silymarin (Bijak, 2017; Abenavoli et al., 2018). Low bioavailability is a major obstacle for biomedical applications of drugs. Therefore, finding a new formulation with high solubility in water and low cost is necessary. In recent years, considerable efforts

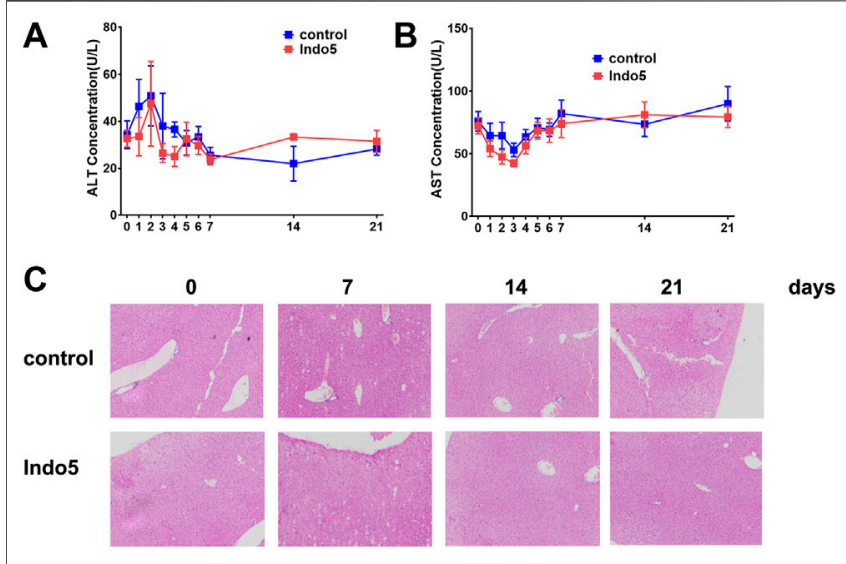

FIGURE 6 | Effects of continuous administration of Indo 5 for 21 days on liver injury in mice. The mice were orally administered with Indo5 $(60 \mathrm{mg} / \mathrm{kg}$, once daily) for 21 days $(n=6)$. Serum levels of ALT (A) and AST (B) were measured at the indicated time points. At the indicated time, the mice were killed for histopathological examination of liver tissue (C). Data are presented as the mean $\pm \mathrm{SD}$. Two-tailed t tests were performed. ${ }^{*} p<0.05$ were regarded as statistically significant, compared with control group.

have been made to improve the oral absorption of insoluble drugs. Drug modifications, including the formation of salts, esters, and complexes with hydrophilic excipients, have been used to optimize silymarin solubility (Chen et al., 2011; Javed et al., 2011; Bonifácio et al., 2014). Most formulation strategies refer to complexation with cyclodextrins or phospholipids ("phytosomes"), solid dispersions stabilized by biocompatible polymers, microemulsions, nanoemulsions, lipid-based delivery systems, biodegradable polymeric nanoparticles, and inorganic nanomaterials (Bilensoy et al., 2008; Dahmani et al., 2012; Li et al., 2015b; Hussain et al., 2016; Yao et al., 2017; Ma and Williams, 2018). Further investigations are needed to improve the oral bioavailability of Indo5.

Investigating the tissue-specific distribution of a compound can reveal much information, including its potential side effects or possibilities for drug repositioning (Esch et al., 2015). Here, we described the biodistribution pattern of Indo5. The highest concentration of Indo5 was detected in the liver after intravenous and oral dosing. Furthermore, Indo5 was not able to cross the blood-brain barrier or blood-testes barriers. The analysis of the toxicity of Indo5 in the liver suggested that continuous oral administration of Indo5 for 21 days had no effect on serum levels of ALT or AST. Moreover, normal tissue architecture was preserved in the Indo5-treated group, and the number of hepatic mononuclear cells, the frequency of different immune-cell subsets, and the activation status of $\mathrm{T}$ cells in the liver were unchanged. These data suggest that, even though Indo5 is most distributed in the liver, it does not cause significant toxicity. Taken together with the result that Indo5 demonstrates antitumor activity and improves overall survival in a mouse hepatic orthotopic model (Luo et al., 2019), our findings imply that Indo5 may be helpful in HCC treatment. 

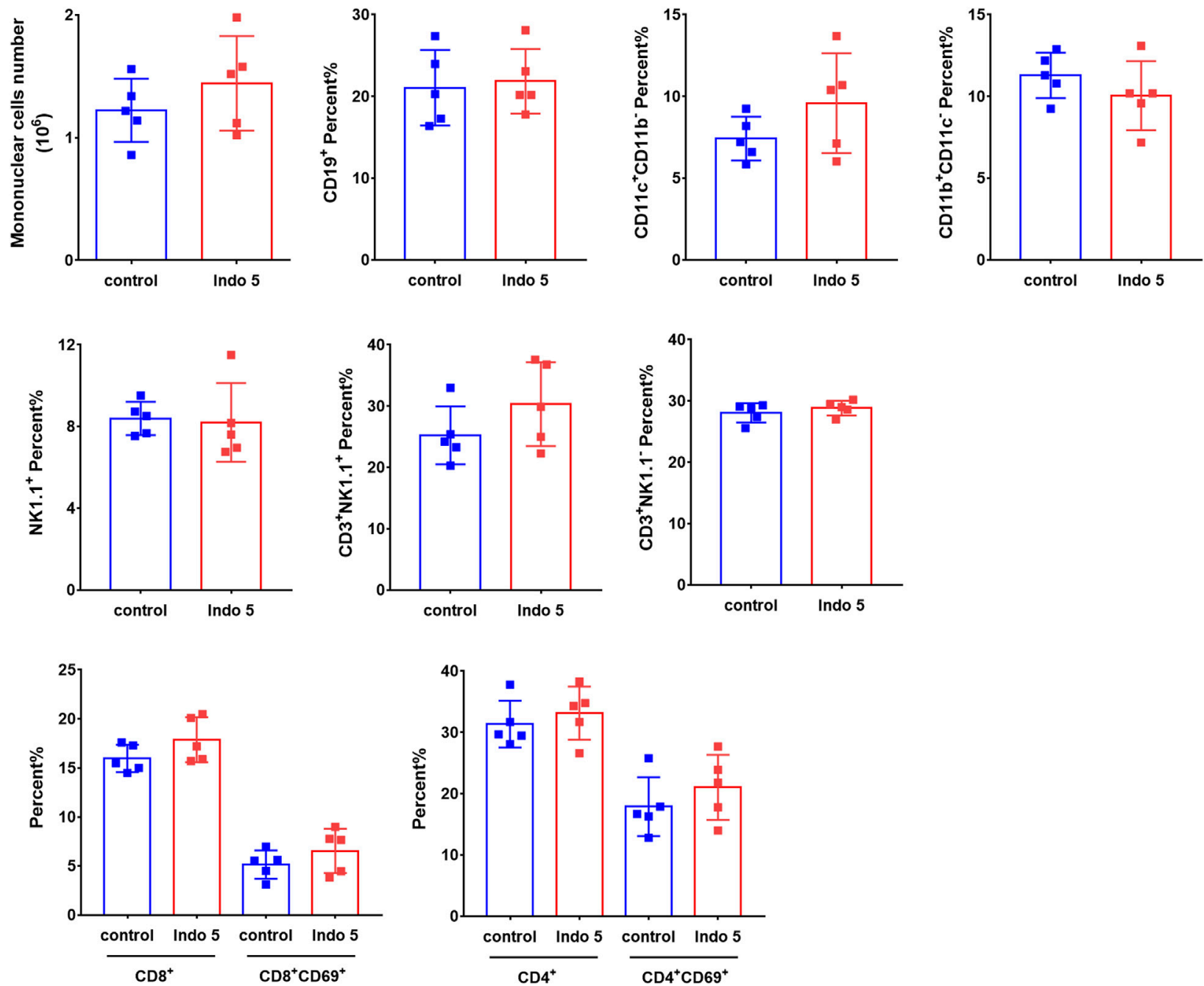

FIGURE 7 | Effects of continuous administration of Indo5 for 21 days on the number and constitution of immune cells in the liver. The mice were orally administered with Indo5 (60 mg/kg, once daily) for 21 days $(n=6)$. On day 21, they were killed, and hepatic mononuclear cells were isolated. The number of liver mononuclear cells and frequencies of T cells $\left(\mathrm{CD}^{+} \mathrm{NK} 1.1^{-}\right)$, NK cells $\left(\mathrm{CD} 3^{-} \mathrm{NK} 1.1^{+}\right)$, NKT cells $\left(\mathrm{CD} 3^{+} \mathrm{NK} 1.1^{+}\right), \mathrm{B}$ cells $\left(\mathrm{CD} 19^{+}\right), \mathrm{DCs}\left(\mathrm{CD} 11 \mathrm{c}^{+} \mathrm{CD} 11 \mathrm{~b}^{-}\right), \mathrm{myeloid}$ cells $\left(\mathrm{CD} 11 \mathrm{~b}{ }^{+} \mathrm{CD} 11 \mathrm{c}^{-}\right), \mathrm{T}^{-}$cell subsets $\left(\mathrm{CD} 4^{+}, \mathrm{CD}^{+}\right)$, and activated T cells $\left(\mathrm{CD} 4^{+} \mathrm{CD} 69^{+}, \mathrm{CD} 8^{+} \mathrm{CD} 69^{+}\right)$were measured using flow cytometry. Data are presented as the mean $\pm \mathrm{SD}$. Two-tailed $\mathrm{t}$ tests were performed. All $p$ values were greater than 0.05 . There was no statistical significance in the number or frequencies of immune cells in the liver between the administration group and the control group.

CONCLUSION

Indo5, a selective inhibitor of c-Met and Trks, is mostly distributed in the liver in vivo. It shows no obvious toxicity or side effects in the liver, which further supports its development as an antitumor treatment for HCC patients.

\section{DATA AVAILABILITY STATEMENT}

The raw data supporting the conclusions of this article will be made available by the authors, without undue reservation.

\section{ETHICS STATEMENT}

The animal study was reviewed and approved by Animal Ethics Committee of the Academy of Military Medical Science (Beijing, China).

\section{AUTHOR CONTRIBUTIONS}

TL: Formal analysis, data curation, and writing (original draft). F-XZ: Formal analysis and investigation. Y-QZ, S-GZ, and LW: Provided drugs and materials. G-FD: Formal analysis. KZ, H-YG, 
TL, MY, and HC: Assisted in animal experiments. X-MY and C-YL: Conception and study design, data analysis and interpretation, article writing, and final approval of the article.

\section{FUNDING}

This study was supported in part by the Ministry of Science and Technology of the People's Republic of China (2017YFA0103400),

\section{REFERENCES}

Abenavoli, L., Izzo, A. A., Milić, N., Cicala, C., Santini, A., and Capasso, R. (2018). Milk Thistle (Silybum marianum): A Concise Overview on its Chemistry, Pharmacological, and Nutraceutical Uses in Liver Diseases. Phytotherapy Res. 32, 2202-2213. doi:10.1002/ptr.6171

Alqahtani, A., Khan, Z., Alloghbi, A., S. Said Ahmed, T., Ashraf, M., and M. Hammouda, D. (2019). Hepatocellular Carcinoma: Molecular Mechanisms and Targeted Therapies. Medicina 55, 526. doi:10.3390/medicina55090526

Bertot, L. C., and Adams, L. A. (2019). Trends in Hepatocellular Carcinoma Due to Non-Alcoholic Fatty Liver Disease. Expert Rev. Gastroenterol. Hepatol. 13, 179-187. doi:10.1080/17474124.2019.1549989

Bijak, M. (2017). Silybin, a Major Bioactive Component of Milk Thistle (Silybum marianum L. Gaernt.)-Chemistry, Bioavailability, and Metabolism. Molecules 22, 1942. doi:10.3390/molecules22111942

Bilensoy, E., Gürkaynak, O., Ertan, M., Şen, M., and Hincal, A. A. (2008). Development of Nonsurfactant Cyclodextrin Nanoparticles Loaded with Anticancer Drug Paclitaxel. J. Pharm. Sci. 97, 1519-1529. doi:10.1002/jps.21111

Bonifácio, B. V., Silva, P. B., Ramos, M. A., Negri, K. M., Bauab, T. M., and Chorilli, M. (2014). Nanotechnology-Based Drug Delivery Systems and Herbal Medicines: A Review. Int. J. Nanomedicine 9, 1-15. doi:10.2147/ijn.s52634

Bruix, J., Qin, S., Merle, P., Granito, A., Huang, Y.-H., Bodoky, G., et al. (2017). Regorafenib for Patients with Hepatocellular Carcinoma Who Progressed on Sorafenib Treatment (RESORCE): A Randomised, Double-Blind, PlaceboControlled, Phase 3 Trial. Lancet 389, 56-66. doi:10.1016/s0140-6736(16) 32453-9

Bruix, J., Tak, W.-Y., Gasbarrini, A., Santoro, A., Colombo, M., Lim, H.-Y., et al. (2013). Regorafenib as Second-Line Therapy for Intermediate or Advanced Hepatocellular Carcinoma: Multicentre, Open-Label, Phase II Safety Study. Eur. J. Cancer 49, 3412-3419. doi:10.1016/j.ejca.2013.05.028

Chen, M.-W., Wang, Y.-T., Wang, S. P., and Zhong, Z. F. (2011). Advances in the Nanoparticle Drug Delivery Systems of Silymarin. J. Chin. Pharm. Sci. 20, 442-446. doi:10.5246/jcps.2011.05.055

Cheng, A.-L., Kang, Y.-K., Chen, Z., Tsao, C.-J., Qin, S., Kim, J. S., et al. (2009). Efficacy and Safety of Sorafenib in Patients in the Asia-Pacific Region with Advanced Hepatocellular Carcinoma: A Phase III Randomised, Double-Blind, Placebo-Controlled Trial. Lancet Oncol. 10, 25-34. doi:10.1016/s1470-2045(08) 70285-7

Dahmani, F. Z., Yang, H., Zhou, J., Yao, J., Zhang, T., and Zhang, Q. (2012). Enhanced Oral Bioavailability of Paclitaxel in Pluronic/LHR Mixed Polymeric Micelles: Preparation, In Vitro and In Vivo Evaluation. Eur. J. Pharm. Sci. 47, 179-189. doi:10.1016/j.ejps.2012.05.015

Esch, E. W., Bahinski, A., and Huh, D. (2015). Organs-On-Chips at the Frontiers of Drug Discovery. Nat. Rev. Drug Discov. 14, 248-260. doi:10.1038/nrd4539

George, S., Wang, Q., Heinrich, M. C., Corless, C. L., Zhu, M., Butrynski, J. E., et al. (2012). Efficacy and Safety of Regorafenib in Patients with Metastatic And/or Unresectable GI Stromal Tumor after Failure of Imatinib and Sunitinib: A Multicenter Phase II Trial. J. Clin. Oncol. 30, 2401-2407. doi:10.1200/ jco.2011.39.9394

Grothey, A., Cutsem, E. V., Sobrero, A., Siena, S., Falcone, A., Ychou, M., et al. (2013). Regorafenib Monotherapy for Previously Treated Metastatic Colorectal Cancer (CORRECT): an International, Multicentre, Randomised, PlaceboControlled, Phase 3 Trial. Lancet 381, 303-312. doi:10.1016/s0140-6736(12) 61900-x
National Natural Science Foundation of China (81770108, 81273543), and the State Key Laboratory of Proteomics (SKLPK201802, SKLP-O201804).

\section{ACKNOWLEDGMENTS}

We thank LetPub (www.letpub.com) for its linguistic assistance during the preparation of this manuscript.

Huizing, M. T., Misser, V. H. S., Pieters, R. C., Ten Bokkel Huinink, W. W., Veenhof, C. H. N., Vermorken, J. B., et al. (1995). Taxanes: a New Class of Antitumor Agents. Cancer Invest. 13, 381-404. doi:10.3109/07357909509031919

Hussain, A., Haque, M. W., Singh, S. K., and Ahmed, F. J. (2016). Optimized Permeation Enhancer for Topical Delivery of 5-Fluorouracil-Loaded Elastic Liposome Using Design Expert: Part II. Drug Deliv. 23, 1242-1253. doi:10.3109/ 10717544.2015.1124473

Javed, S., Kohli, K., and Ali, M. (2011). Reassessing Bioavailability of Silymarin. Altern. Med. Rev. 16, 239-249. doi:10.1016/j.eujim.2011.05.002

Li, Y., Gao, Z.-H., and Qu, X.-J. (2015a). The Adverse Effects of Sorafenib in Patients with Advanced Cancers. Basic Clin. Pharmacol. Toxicol. 116, 216-221. doi: $10.1111 /$ bcpt. 12365

Li, Y., Zhao, X., Zu, Y., and Zhang, Y. (2015b). Preparation and Characterization of Paclitaxel Nanosuspension Using Novel Emulsification Method by Combining High Speed Homogenizer and High Pressure Homogenization. Int. J. Pharmaceutics 490, 324-333. doi:10.1016/j.ijpharm.2015.05.070

Liu, G., Franssen, E., Fitch, M. I., and Warner, E. (1997). Patient Preferences for Oral versus Intravenous Palliative Chemotherapy. J. Clin. Oncol. 15, 110-115. doi:10.1200/jco.1997.15.1.110

Llovet, J. M., Ricci, S., Mazzaferro, V., Hilgard, P., Gane, E., Blanc, J.-F., et al. (2008). Sorafenib in Advanced Hepatocellular Carcinoma. N. Engl. J. Med. 359, 378-390. doi:10.1056/NEJMoa0708857

Luo, T., Zhang, S.-G., Zhu, L.-F., Zhang, F.-X., Li, W., Zhao, K., et al. (2019). A Selective C-Met and Trks Inhibitor Indo5 Suppresses Hepatocellular Carcinoma Growth. J. Exp. Clin. Cancer Res. 38, 130. doi:10.1186/s13046019-1104-4

Ma, X., and Williams, R. (2018). Polymeric Nanomedicines for Poorly Soluble Drugs in Oral Delivery Systems: An Update. J. Pharm. Invest. 48, 61-75. doi:10.1007/s40005-017-0372-2

Oostendorp, R. L., Buckle, T., Lambert, G., Garrigue, J. S., Beijnen, J. H., Schellens, J. H. M., et al. (2011). Paclitaxel in Self-Micro Emulsifying Formulations: Oral Bioavailability Study in Mice. Invest. New Drugs 29, 768-776. doi:10.1007/ s10637-010-9421-7

Pan, H., Fu, X., and Huang, W. (2011). Molecular Mechanisms of Liver Cancer. Anticancer Agents Med. Chem. 11, 493-499. doi:10.2174/187152011796011073

Rowinsky, E. K., Wright, M., Monsarrat, B., and Donehower, R. C. (1994). Clinical Pharmacology and Metabolism of Taxol (Paclitaxel): Update 1993. Ann. Oncol. 5 (Suppl. 6), S7-S16.

Schellens, J. H. M., Malingré, M. M., Kruijtzer, C. M. F., Bardelmeijer, H. A., Van Tellingen, O., Schinkel, A. H., et al. (2000). Modulation of Oral Bioavailability of Anticancer Drugs: from Mouse to Man. Eur. J. Pharm. Sci. 12, 103-110. doi:10.1016/s0928-0987(00)00153-6

Shen, Y.-C., Lin, Z.-Z., Hsu, C.-H., Hsu, C., Shao, Y.-Y., and Cheng, A.-L. (2013). Clinical Trials in Hepatocellular Carcinoma: An Update. Liver Cancer 2, 345-364. doi:10.1159/000343850

Sia, D., Villanueva, A., Friedman, S. L., and Llovet, J. M. (2017). Liver Cancer Cell of Origin, Molecular Class, and Effects on Patient Prognosis. Gastroenterology 152, 745-761. doi:10.1053/j.gastro.2016.11.048

Stewart, B. W., and Wild, C. P. (2014). World Cancer Report. Geneva, Switzerland: World Health Organization, International Agency for Research on Cancer.

Stotz, M., Gerger, A., Haybaeck, J., Kiesslich, T., Bullock, M. D., and Pichler, M. (2015). Molecular Targeted Therapies in Hepatocellular Carcinoma: Past, Present and Future. Anticancer Res. 35, 5737-5744. https://ar.iiarjournals.org/content/35/11/5737.long

Sun, L., Tran, N., Tang, F., App, H., Hirth, P., Mcmahon, G., et al. (1998). Synthesis and Biological Evaluations of 3-Substituted Indolin-2-Ones: a Novel Class of 
Tyrosine Kinase Inhibitors that Exhibit Selectivity toward Particular Receptor Tyrosine Kinases. J. Med. Chem. 41, 2588-2603. doi:10.1021/jm980123i

Talbi, A., Zhao, D., Liu, Q., Li, J., Fan, A., Yang, W., et al. (2014). Pharmacokinetics, Tissue Distribution, Excretion and Plasma Protein Binding Studies of Wogonin in Rats. Molecules 19, 5538-5549. doi:10.3390/molecules 19055538

Yao, Q., Gutierrez, D. C., Hoang, N. H., Kim, D., Wang, R., Hobbs, C., et al. (2017). Efficient Codelivery of Paclitaxel and Curcumin by Novel Bottlebrush Copolymer-Based Micelles. Mol. Pharmaceutics 14, 2378-2389. doi:10.1021/ acs.molpharmaceut.7b00278

Conflict of Interest: The authors declare that the research was conducted in the absence of any commercial or financial relationships that could be construed as a potential conflict of interest.
Publisher's Note: All claims expressed in this article are solely those of the authors and do not necessarily represent those of their affiliated organizations, or those of the publisher, the editors and the reviewers. Any product that may be evaluated in this article, or claim that may be made by its manufacturer, is not guaranteed or endorsed by the publisher.

Copyright $\odot 2021$ Luo, Zhang, Zhao, Gao, Zhang, Wang, Dou, Liu, Yu, Zhan, Chen, Yang and Li. This is an open-access article distributed under the terms of the Creative Commons Attribution License (CC BY). The use, distribution or reproduction in other forums is permitted, provided the original author $(s)$ and the copyright owner(s) are credited and that the original publication in this journal is cited, in accordance with accepted academic practice. No use, distribution or reproduction is permitted which does not comply with these terms. 